\title{
Continuidades: Consenso y cooperación en la formulación de la seguridad transicional en Chile (1986-1994) 1
}

Continuities: Consensus and cooperation in transitional security formulation in Chile (1986-1994)

Camilo MORA ZAVALA2

Universidad de Santiago de Chile camilo.mora2@gmail.com

\section{Resumen}

El presente artículo tiene por objeto relevar los aspectos de continuidad que intervienen en la construcción de una política de seguridad en la transición chilena a la democracia, durante el primer gobierno de postdictadura encabezado por Patricio Aylwin (1990-1994). Se sostiene que la adopción de esta política se habría dado gracias a un consenso político previo que se desarrolla en tres fases: consenso intraoposición, consenso cívico-militar y consenso abierto, los que se extienden principalmente entre 1986 y 1994.

Palabras Clave: consenso; terrorismo; seguridad; transición.

\begin{abstract}
The purpose of this article is to survey the continuity aspects that intervene in the construction of a security policy in the Chilean transition to democracy, during the first post-dictatorship government headed by Patricio Aylwin (1990-1994). It is argued that the adoption of this policy would have occurred thanks to a previous political consensus that is developed in three phases: intra-opposition consensus, civic-military consensus and widespread consensus, which developed mainly betwen 1986 and 1994.
\end{abstract}

Keywords: consensus; terrorism; security; transition.

1 Este trabajo es una profundización temática del cuarto capítulo de nuestra tesis de maestría, titulada "Revolución, mito y transición: el mito transicional como disciplinamiento ideológico en Chile, 1988-1994" (2020).

Continuidades: Consenso y cooperación en la formulación de la seguridad transicional en Chile (19861994)

Sur y Tiempo. Revista de Historia de América, №4, julio-diciembre 2021, pp. 70-89.

ISSN 2452-574X

DOI: $10.22370 /$ syt.2021.4.2913 


\section{Introducción}

En el mes de marzo del presente año 2021, los periodistas Dauno Tótoro y Javier Rebolledo publicaron su libro titulado Rati. En esta investigación periodística Tótoro y Rebolledo recogieron el testimonio de Jesús Silva San Martín, un exagente de la policía de Investigaciones y también agente de la coloquialmente conocida Oficina, organismo de seguridad durante el primer gobierno transicional.

Una de las tensiones más visibles en él es la delgada línea que separa a quienes fueron considerados por estos agentes como los buenos y los malos. Esto, precisamente porque, como señalan Tótoro y Rebolledo, la tarea de desarticular a las organizaciones subversivas "se había entreverado con una guerra sucia y soterrada, con informantes de un lado y otro, traiciones, crímenes, torturas, todo parte de una amalgama gris y opaca donde -aseguran los autores- los valores morales estaban condenados a morir de la peor forma" (Tótoro y Rebolledo, 2021: 11). Pero más específicamente, porque, como ellos sugieren, "al escucharlo nos dimos cuenta que estaba abriendo una caja de Pandora, donde habitan políticos reconocidos, policías, periodistas, empresarios, abogados y supuestos izquierdistas, todos con algo en común: habían excedido las consideraciones éticas que sostenían como inviolables" (Tótoro y Rebolledo, 2021: 12).

Las reflexiones hechas por esta investigación periodística nos invitan a relanzar algunas preguntas relativas a la naturaleza histórica de ese entrevero y la trama geopolítica que subyace al clima de violencia política y conflicto social durante el primer gobierno transicional conducido por Patricio Aylwin (1990-1994). Resulta evidente que algunos de los factores relevantes en la complejidad de las líneas divisorias en lo político y lo moral a comienzos de la década de 1990, vienen dados por algunos elementos de continuidad en torno a la construcción de una política de seguridad transicional que se balancea entre el desarrollo de un conflicto no resuelto, el consenso político y la cooperación.

La transición chilena a la democracia y el gobierno de Patricio Aylwin (19901994) se desarrolló en torno a cuatro desafíos estratégicos, los cuales buscaron asegurar las bases de un proyecto nacional, lograr gobernabilidad, consolidar la democracia y dar término a la transición (Boeninger, 1997: 379-385). Sin embargo, el esfuerzo por reorganizar las relaciones entre el Estado y la sociedad civil, así como el de reorientación de las FF.AA., no necesariamente proscribió el conflicto social precedente. Por un lado, persistió el temor a una regresión autoritaria y se introdujeron nuevas tensiones derivadas de la continuidad de Augusto Pinochet como Comandante en Jefe del Ejército y, luego, en las labores legislativas en calidad de senador vitalicio (Soto, 2009); por el otro, las acciones de algunas organizaciones

2 Chileno. Estudiante de Doctorado en Historia, Becario ANID Doctorado Nacional 2021, folio $\mathrm{N}^{\circ} 21211791$. 
de la izquierda armada estimulaban las tareas de gobierno en materia de seguridad (Rosas, 2004), ponían en tensión la consecución de sus cuatro desafíos estratégicos y también sus relaciones con la derecha política.

De acuerdo a algunas investigaciones, constan dos cosas en el período que va del año 1990 a 1994: la primera, es que aumenta significativamente la preocupación pública por la violencia delictual y la seguridad ciudadana (Ramos y Guzmán, 2000; Acevedo, 2017; Dammert, 2004; De Rentemería, 2005); la segunda es que tiene lugar un cambio en la estrategia de seguridad interna, que puede verse materializada tanto en el distanciamiento de la Doctrina de Seguridad Nacional (DSN), como, posteriormente, en la formación del Consejo Coordinador de Seguridad Pública (CCSP, "La Oficina") y la posterior adopción de la Doctrina de la Seguridad Ciudadana (DSC).

A este respecto, sabemos que esta transición, en lo relativo a seguridad, se hizo mediante un tipo de asociación de la demanda social con el delito, en una política de contención del malestar social (Pincheira, 2014), una resignificación simbólica de la violencia política ahora comprendida como delictual (Celis, 2010), o asociando en el imaginario colectivo problemas sociales como la delincuencia común y la pobreza con la violencia política entendida como terrorismo, permitiendo la criminalización de la protesta social y su reinterpretación en clave de marginalismo (Acevedo, 2017). Sin embargo: ¿qué permitió esa asociación y cambio en la política de seguridad? ¿Qué posibilita implementar tales dispositivos? ¿Cómo se alcanza esa noción predominante de terrorismo en el período transicional?

Creemos que la transición en materia de seguridad comienza informalmente a mediados de 1980 con ideas generalizadas entre la oposición a la dictadura en torno a concepciones contrasubversivas de la violencia política, de la izquierda revolucionaria y de la protesta social. Esta generalización de ideas habría comenzado a tomar forma de consenso político y estuvo orientada por los principales actores de la elite política vinculada a la Concertación y cuyo registro conceptual valorizó el término terrorismo, propiciando el aislamiento social de los sectores rupturistas, con lo cual la posterior transformación doctrinaria y formación de los organismos de seguridad está posibilitado por parte de una estrategia política con desarrollo previo.

Asimismo, este consenso habría exigido colaboración cívico militar. Primero, ante la persistencia de grandes presiones políticas de los partidos de derecha y militares; segundo, para evitar la regresión autoritaria; tercero, buscando restablecer el equilibrio democrático en Chile, en función de la unidad del Chile antagónico. De este modo, el consenso se habría dado en tres etapas: Consenso intra-oposición 1983-1986; Consenso cívico-militar entre los años 1988-1990; Consenso abierto desde finales del año 1990 en adelante. 
En este sentido, el presente artículo intentará desarrollar una reflexión histórica a partir de algunos antecedentes sobre consenso y cooperación en materia de seguridad de manera previa a la transición democrática en 1990, sugiriendo una posible categorización de esta dinámica, para finalmente introducirse en el análisis de algunos eventos relevantes que los ponen a prueba hasta el año 1994.

Para ello, hemos hecho revisión de fuentes primarias oficiales, fundamentalmente extraídas del fondo digital del período presidencial de Patricio Aylwin (abreviaremos: FPP), perteneciente al Archivo Institucional de la Universidad Alberto Hurtado, prensa y revistas de oposición, así como también algunas fuentes partidarias y otras secundarias que, producidas en el contexto histórico referido, tienen un valor testimonial e informativo. Las fuentes oficiales nos han permitido acceder a la óptica intra-gobierno, permitiéndonos dar seguimiento a las preocupaciones del mismo, pero también a las disposiciones adoptadas frente a los diferentes momentos que enfrenta a propósito del conflicto político, dando cuenta de los sujetos relevantes en la toma de decisiones y también la dirección de las tensiones que introduce. Mediante la prensa periódica, daremos seguimiento y reconstrucción parcial de algunos hechos, sumando voces y datos relevantes en relación a la discusión pública en materia de seguridad. Mientras que con las fuentes secundarias seleccionadas y la bibliografía específica, buscaremos elevar la reflexión hacia conclusiones parciales sobre los apartados ofrecidos.

\section{Cuestiones generales}

El núcleo de investigaciones existente en relación a las políticas de seguridad ha permitido establecer que las consideraciones en torno a esta variaron, implicando, en el plano nacional, la redefinición de la función militar de acuerdo al nuevo marco jurídico (Arévalo, 2003). También, que estas reestructuraciones en materia de seguridad en Argentina, Brasil, Perú y Chile derivaron en la creación de organismos nuevos o adecuaciones de los anteriores (Maldonado, 2002) y que, en una relación más amplia, estuvieron influidos por el cambio en el escenario estratégico mundial, por los procesos de democratización y los cambios en la política exterior norteamericana hacia América Latina (Hens y Sanahuja, 1995: 58-69).

Los estudios más focalizados en Chile sitúan el surgimiento de la llamada Doctrina de Seguridad Ciudadana (DSC) a inicios de la década de 1990. Y entre estos, hay quienes señalan además su importancia política en toda la postdictadura y como un elemento que se erige como relevante en la elaboración de políticas públicas, como un momento de implantación del miedo y delegación de responsabilidades sociales a la seguridad privada (Ramos y Guzmán, 2000; De Rentemería, 2005). Se ha planteado que, a diferencia de la anterior DSN, la DSC se preocupó de las diversas manifestaciones de criminalidad e inseguridad que alteraron los indicadores de 
calidad de vida (Beroíza, 2016), caracterizado por el uso de los dispositivos legales, más que la coerción, para tratar tanto la violencia política como delictual (Sáez, 2017; Ramos y Guzmán, 2000). Sin embargo, queda pendiente desentrañar la relación política subyacente a una determinada lógica de seguridad y represión adoptada en este ciclo. Aquellas explicaciones que dan cuenta del cambio en el cuerpo doctrinario y han intentado explicar a partir de allí la represión hacia la izquierda armada no han indagado en las expresiones políticas consensuadas de ese cambio. Mientras que sobre el lugar de la violencia en este período las evaluaciones suelen ser dispares.

Por un lado, se ha planteado que las acciones armadas de las organizaciones revolucionarias, a inicios de los noventa, fueron combatidas con las "armas de la democracia" y concebidas como terrorismo (Goicovic, 2010) y que, de los resultados desestabilizadores de sus acciones surgió la necesidad de “destruirlos" (Sáez, 20173; Beroíza, 2016: 161). Por otro, tanto en las evaluaciones de Frühling y Weise (1995) como las de Acevedo (2017), las acciones de violencia política no fueron un problema particularmente complejo para el gobierno transicional, ni por la envergadura de estas, ni por el riesgo de comprometer la estabilidad democrática y la seguridad del Estado. Según este enfoque, más influyeron las presiones de la oposición que pujaban por la participación de las FF.AA. en estos asuntos, a objeto de obtener un lugar más relevante en la iniciativa de la represión.

Estos enfoques son parcialmente correctos y pueden constatarse. Pero también cabe consignar que el enfoque que relaciona acción y reacción pierde perspectiva histórica y dificulta la observación del fenómeno de acuerdo a su desarrollo particular, anteponiéndole el tiempo institucional. Otra cosa, es que las presiones de la derecha son también permanentes producto del respaldo militar tanto en el ejercicio parlamentario como desde las FF.AA.

En términos generales, si revisamos un episodio clave de este período en esta materia podemos observar algunas líneas más transversales de nuestro problema. El asesinato de Jaime Guzmán el día 1 de abril de 1991, sí fue considerado excepcional o punto de inflexión, ya sea porque, dependiendo del análisis, precipita la adopción, por parte del gobierno, de una política de seguridad ante las presiones por involucrar a los militares en esta tarea (Acevedo: 2016), o porque implicó una cierta "derrota" para sus autores, o bien por que desplazó el debate sobre las violaciones de derechos humanos o el terrorismo de Estado, hacia la violencia política (Loveman y Lira, 2000: 524; Frühling y Weiser, 1995). De hecho, para Frühling y Weiser, en un libro compilatorio del año 1995 sobre estas materias, con el asesinato de Guzmán "se profundizó el consenso político en contra de las acciones terroristas" (Frühling y Weiser, 1995: 102). Esto, en primer lugar, sugiere la existencia de un consenso

3 Esto está planteado en el marco de lo que considera como la "represión renovada", proceso que se extiende de finales de los ochenta hasta 1994. 
previo que tiende a profundizarse. Luego, ello abre preguntas acerca de los antecedentes de ese consenso, su naturaleza, los actores del consenso y su contenido.

Nuestra propuesta es: a) reconsiderar el factor político nacional de las motivaciones que dieron por resultado las transformaciones en esa lógica de seguridad para considerar la existencia de un consenso político previo; y b) superar las subsunciones del fenómeno al corte temporal y la superposición mutua a que tienden estos. Principalmente, porque el consenso político en torno a las nociones de terrorismo y seguridad, vinculado a los hechos de violencia, sugiere algo más que reacción y porque el cambio de políticas de seguridad sugiere que, anterior a un consenso, habría una o varias estrategias en desarrollo.

\section{Consenso intra-oposición: democracia y antiterrorismo}

Si bien las categorías de terrorismo y subversión movilizadas durante el período de dictadura en Chile y empleadas para denominar el fenómeno de la violencia política, pueden insertarse en una lógica de mayor escala temporal y geográfica (González, 2009: 119-137), es importante relevar las motivaciones locales en este aspecto.

Las nociones de violencia política fueron diversas y en cierto ámbito se incorporó las de terrorismo y subversión con rasgos de anticomunismo visibles. Esto último puede verse en diversas publicaciones destinadas a la circulación militar y civil, predeciblemente vinculados a la derecha política que, además, dan cuenta de una actividad política pública (Fuentes, 1981)4. Sin embargo, resulta más peculiar que se hallen también estas conceptualizaciones entre los sectores políticos que durante la década de los ochenta en Chile, conforman la oposición a la dictadura militar. Así, por ejemplo, durante las Jornadas Nacionales de protesta, entre 1983 y 1986, algunos de los sectores que posteriormente conformarían la Concertación de Partidos por la Democracia, adoptaron tempranamente estas ideas asociándolas al restablecimiento democrático. Es así como aparecen, durante la formulación del Acuerdo Nacional, expresas referencias al terrorismo (violencia política de los grupos armados de izquierda y de la dictadura) como conducta antidemocrática. Algunos prohombres de la democracia cristiana adoptaron también esta idea, difundiéndola como parte de su entramado de pensamiento (Frei, 1984; Velasco,

\footnotetext{
4 También contamos, en este caso, con algunas fuentes secundarias, entre las que podemos destacar: Dirección de Instrucción del Ejército, "El Marxismo-Leninismo. Análisis Crítico", Estado Mayor General del Ejército, 1984; Ministerio del Interior, "Latinoamérica Frente al Terrorismo", Oficina del Abogado Procurador General de la República-Universidad de Chile, 1987; S/A, "Insurrección no violenta", Instituto Nacional de Estudios Histórico-Culturales, Secretaría FEAL-CENSUR, Editorial Cono Sur, Asunción, sin año. En el caso de este último texto, dado que ninguna referencia supera en marco
} 
1986). A juicio de Eduardo Frei Montalva, la dictadura había servido como caldo de cultivo para "otro extremo" de la violencia. Estos extremos no se distinguirían más que por su sentido (Frei, 1984: 18-23).

En un tono mucho más pragmático el documento Bases del diálogo para un Gran Acuerdo Nacional, de 1983, señalaba en su punto $N^{\circ} 21$ que "se garantizará la existencia y funcionamiento de todas las organizaciones políticas que se comprometan con los principios democráticos, condenándose toda acción terrorista que atente contra el régimen democrático y se promoverán las iniciativas judiciales para resguardar la vida de las personas y la integridad de sus bienes. Se tipificarán con rango constitucional las conductas antidemocráticas, con el fin de establecer penalidades en caso de que sea sobrepasada la legalidad. No se sancionarán las ideas sino los actos de personas y organizaciones que se consideren delictuales" 5 . Claramente comienzan a aparecer nociones de terrorismo asociadas a delito y su rechazo en calidad de antidemocrático.

Los diferentes sectores políticos de la oposición comenzaron a manifestarse sobre la violencia política bajo el rótulo común del terrorismo. Mario Sharpe, de la Social Democracia, señaló en 1984 que "no aceptamos el terrorismo de extrema derecha, de extrema izquierda o los excesos de la fuerza pública". En esta misma línea defiende la transición pacífica recalcando que "condenamos la violencia, la del Régimen y la de cualquiera de los extremos"6.

Asimismo, el Bloque Socialista, en 1984, rechazaba el terrorismo de Estado y precisaba que "con igual claridad condenamos el uso del terrorismo como arma de la oposición, especialmente porque este se ejerce en forma indiscriminada y en contra de personas inermes, como ocurrieron en el reciente atentado a la Bolsa de Comercio", pues según el documento estas acciones servirían a la dictadura para imponerse con mayor fuerza contra un supuesto estado social caótico ${ }^{7}$.

Durante 1986, el "Año Decisivo", algunos documentos de la oposición reflejaban incipientemente algunos de estos consensos sobre violencia política.

Gabriel Valdés S. en carta a la Comisión Política del PCCh, a nombre del PDC, en 1986 sobre el atentado a Augusto Pinochet, señalaba: "a nuestro juicio, el P.C. viene sosteniendo una estrategia que juzgamos condenable." Para precisar luego que "a lo largo de los últimos años, hemos reiterado una y otra vez, en cartas a la dirección de vuestro Partido, que la llamada estrategia de 'rebelión popular' sostenida por Uds. no sólo es conducente a actos terroristas -que siempre son infamantes para el que los comete sino que, además, divide profundamente a la

temporal el año 1984 y refiere permanentemente a las protestas nacionales, inferimos que su año de edición debe ser mediados de la década de los ochenta.

5 "Bases del Diálogo para un Gran Acuerdo Nacional", 22 de agosto, 1983, p. 5.

6 Análisis, $\mathrm{N}^{\circ} 73,17$ al 31 de enero, 1984, p. 24.

7 "El Bloque Socialista ante la Profunda Crisis que vive el País", 20 de diciembre de 1984. 
oposición..."8. Son principalmente los hechos de 1986 (atentado a Pinochet y decomiso de armas en Carrizal Bajo) los que estimulan las más claras declaraciones sobre la violencia política. De manera posterior Gabriel Valdés señala sobre un posible acuerdo con el PC que "ya es hora de que el PC adopte una definición, no solamente en las palabras sino en los hechos, frente a la violencia y el terrorismo"

Por su parte, el PSCh se sumaba a las declaraciones de rechazo, planteando que "no deseamos la violencia y por ello buscamos la construcción de un régimen en que las legítimas diferencias sean resueltos por medios políticos pacíficos y democráticos. [...] La izquierda rechaza el terrorismo y la militarización de la política", de la cual sería principalmente responsable el régimen 10.

El documento "Acuerdo Nacional para la Transición a la Plena Democracia", de 1986, señalaba que

en la medida en que la convivencia nacional garantice mayor justicia y seguridad para todos, será posible mantener el orden público, evitar el empleo de la violencia, contribuir a eliminar el terrorismo y sancionar las conductas antidemocráticas. En cualquier caso, el resguardo efectivo de los derechos humanos será una preocupación preferente en el quehacer de las autoridades públicas 11 .

Desde la óptica general del Acuerdo Nacional, la condena de la violencia política era requisito de cualquier posibilidad de futuro democrático, por lo cual la violencia política era esencialmente antidemocrática. Este documento puede considerarse como una expresión del consenso político y de carácter colectivo en torno a muchos temas relativos a la transición, la violencia política entendida como terrorismo, es uno de ellos.

Este breve repaso, nos permite observar la singular amplitud que había alcanzado ya hacia el año 1986 la idea del terrorismo como sinonimia de diferentes expresiones de violencia política.

\section{Consenso cívico-militar: Seguridad Nacional y Defensa Nacional}

Los acercamientos entre civiles de la oposición y militares en materia de seguridad y defensa fueron previos a la restitución del Estado de derecho. De hecho, con la búsqueda de regulación de las relaciones entre civiles y militares, también vino la proyección estratégica de los militares con respecto a la defensa. No obstante,

\footnotetext{
8 "Carta de respuesta del Partido Demócrata Cristiano a la Comisión Política del Partido Comunista", 17 de septiembre de 1986.

9 Apsi, N¹86, 25 de agosto al 7 de septiembre de 1986, p. 8.

10 Revista Unidad y Lucha, N99, diciembre de 1986, p. 6.

11 “Acuerdo Nacional para la Transición a la Plena Democracia”, p. 141.
} 
de manera posterior estos acercamientos también tuvieron expresiones más pragmáticas.

Por ejemplo, al alero del Centro de Estudios del Desarrollo (CED) 12, se realizaron entre 1988 y 1989 algunos foros acerca de las relaciones entre militares y civiles, los cuales constituyeron los primeros acercamientos formales. Y hacia 1990, ya recuperada la democracia y con la intención de lograr un entendimiento con el mundo militar, se realizaron 11 talleres que contaron con la presencia de militares nacionales y extranjeros, así como académicos de la Pontificia Universidad Católica de Chile, la Universidad de Chile y especialistas de la Facultad Latinoamericana de Ciencias Sociales (FLACSO) como Carlos Portales y Augusto Varas ${ }^{13}$ (Fuentes Vera, 2009: 87-89).

En otros aspectos, este acercamiento tuvo expresiones materiales en medio de las tensiones al comienzo de la transición. Si bien la dinámica general onduló entre restricciones y concesiones nada impidió, por ejemplo, que, en noviembre de 1990, el Congreso aprobara, sin modificaciones, un presupuesto de $\$ 1200$ millones de pesos para la Defensa Nacional, destinado a mantener unos novecientos contratos de empleados civiles de la ex CNI que se incorporaron a la Dirección Nacional del Ejército, DINE14. Sin embargo, ese, a su vez, tampoco fue impedimento para que el ejército conservara su lugar de presión política. De manera posterior estos realizaron movimientos de tropa en Santiago, en los eventos conocidos como "ejercicio de enlaces", del 20 de diciembre de 1990 y el "boinazo", del 28 de mayo de 1993, destinados a amedrentar al poder ejecutivo y judicial en relación a las causas que se seguían contra el hijo de Augusto Pinochet y algunos de sus oficiales.

En este sentido, la cuestión relativa a seguridad transitaba dos vías a veces paralelas. Por una parte, estas relaciones transitaban las sendas del conflicto social y político que expresaba sus tensiones en un espacio más público y, por otra, se ensayaban las modificaciones y acercamientos de las FF.AA., y en particular del ejército, en relación a las tareas de gobierno en donde los militares buscaron un nicho de participación en el nuevo escenario.

Según el politólogo de la ANEPE, Juan Fuentes Vera, Pinochet instruyó al entonces coronel Juan Emilio Cheyre, Director de la Academia de Guerra, para que "transformara a su institución en una instancia de discusión, formación y acercamiento entre civiles y militares interesados en los temas de la defensa, contribuyendo así a constituir lo que después se denominaría "la comunidad de

\footnotetext{
12 Fundado en 1980 por el demócrata cristiano Gabriel Valdés Subercaseaux.

13 Varas mantuvo colaboraciones con la Academia Nacional de Estudios Políticos y Estratégicos, creada en 1982. Cabe señalar que, previamente, la ANEPE se conoció como Academia de Defensa Nacional (1947) y luego Academia Superior de Seguridad Nacional, en 1974.

$14 \mathrm{Al}$ mes de octubre de 1990, el personal civil contratado por el Ejército, proveniente de la disuelta CNI, ascendía a un total de 1.119 personas. Detalles en el documento "Reunión Ejército", 18 de junio de 1991.
} 
defensa" (Fuentes Vera, 2009: 92). Así, el 4 y 6 de septiembre de 1991 se realizaron las actividades en la Academia de Guerra, en el marco del Seminario sobre Política y Defensa.

Solo unos años más tarde, y depositando los problemas de la seguridad y la defensa nacional en las más altas esferas de lo político y militar, aparecerán, hacia el segundo gobierno de la Concertación, los Libros de la Defensa Nacional, cuyo objetivo sería la concreción de un consenso y superación de la polarización a este respecto (Fuentes Vera, 2009: 110-111). Una vez relativamente circunscritos los límites de la defensa y la seguridad nacional, la Concertación debió enfrentar la persistencia del conflicto político social.

\section{Consenso abierto: colaboración, antiterrorismo y seguridad}

Las relaciones cívico-militares se caracterizaron por sus tensiones, sin embargo, hubo algún grado de colaboración. Esta se desarrolló, con más o menos éxito, en torno al esclarecimiento de las violaciones de los derechos humanos, la normalización democrática y la lucha contra el ahora llamado terrorismo. El restablecimiento de las relaciones entre civiles y militares fue considerado como una tarea fundamental en la propuesta de "unidad nacional" del presidente Aylwin15.

Durante los primeros días tras la restitución democrática y a propósito de los atentados del día 22 de marzo de 1990 contra el ex Comandante en Jefe de la Fuerza Aérea de Chile, General del aire Gustavo Leigh, y el General Enrique Ruiz Bunger, el gobierno vio tensar sus relaciones con los militares, las que a juicio de la revista Análisis ya eran "excesivamente cálidas a los ojos de una parte de la población"16.

Pero pese a lo anterior, Enrique Correa, secretario general de gobierno, declaró para El Mercurio que Patricio Aylwin habría solicitado información a Pinochet sobre el cumplimiento en la disolución de la CNI y además "le requirió [...] que los antecedentes e informaciones que ésta acumuló durante su existencia legal sean puestos a disposición del Gobierno, al servicio de su acción para prevenir y combatir el terrorismo"17. Asimismo, en el contexto de estas tensiones y en cuanto a Carabineros, la revista Hoy consignaba que el general Rodolfo Stange (ex integrante de la Junta Militar), "ha optado por un cómodo accionar fuera del debate,

\footnotetext{
15 El Mercurio, 22 de junio de 1990, p.1. Rodolfo Stange aseguró, más tarde, en correspondencia a Patricio Aylwin que, tras recibir una copia del Informe Rettig, tanto él como Carabineros "se esforzarán por buscar los mejores medios para lograr la reconciliación a que todos aspiramos". Stange, R. "Correspondencia del General Director de Carabineros de Chile al Presidente Patricio Aylwin", Archivo Período Presidencial, 3 de marzo de 1990, 1 pág.

16 Análisis del 7 al 13 de mayo de 1990, p. 8.

17 El Mercurio, 29 de marzo de 1990, Cuerpo A, p.12. En la misma noticia se recogen las declaraciones de Pinochet, en las cuales señala que "El Presidente pidió colaboración porque está complicado por este auge que ha tenido el terrorismo y la subversión. Yo le dije que muy bien, que lo iba a ver, que no hay ningún problema". Ídem.
} 
asegurándole a Carabineros un rol preponderante en el control del terrorismo y en la seguridad de la Presidencia"18.

Del mismo modo, los documentos oficiales de gobierno daban cuenta de las preocupaciones e iniciativas en materia de violencia política entendida como terrorismo. Algunos de sus estrategas, como Edgardo Boeninger, consideraban que "es importante tomar conciencia de que estamos frente a un fenómeno terrorista en Chile, el que actúa en forma permanente, con organización y recursos", refiriéndose especialmente al FPMR19. Sin embargo, las propuestas políticas más concretas comienzan a aparecer hacia 1991, todavía antes del asesinato de Guzmán. En ellas, se observa ya la tendencia descrita al consenso, a las concepciones funcionalistas de la violencia y a la desactivación del conflicto social.

Genaro Arriagada presentó en un seminario organizado por la Comisión de Derechos Humanos sobre violencia y DD.HH. en enero de 1991, diez proposiciones para la lucha antiterrorista. Estas se basaron en: A) unidad frente a la "amenaza" y la concepción de que "el terrorismo es como una peste"; B) Aislamiento de la amenaza mediante marco jurídico y moral y "moderación del uso de la fuerza"; C) Táctica: Debe ajustarse al marco legal, pues si se los convierte en víctimas, la táctica del aislamiento se ve perjudicada; D) Moderación en el uso de fuerza, considerando que bajo su perspectiva, los terroristas usan la represión como un elemento de derrota hacia el Estado; E) La penalización no es el tema primordial, ya que, a su juicio "los terroristas son un tipo de fanáticos al que no le importa si su castigo va a ser mediano, grande o enorme"; F) eficacia de la policía y servicios de inteligencia, sobre la base de un código moral determinado, diferente de la dictadura. Esa eficacia se ve mermada por la destrucción de información acumulada de los servicios anteriores; G) Requerimiento de inteligencia tecnologizada (característica que atribuye a los grupos); H) Establece tres grupos de "alto riesgo". Uno está constituido por el FPMR, MIR, MJL; el segundo la ultraderecha; el tercero son aquellos vinculados a las disueltas DINA-CNI; I) Propone metodologías como: delación e infiltración; J) Reforma al sistema carcelario, construcción de cárceles de alta seguridad, donde estén aislados 20 .

De manera posterior, estas expresiones se multiplicarían en la política oficial con participación de diversos sectores políticos, asentando el diagnóstico de la existencia de terrorismo y buscando "continuar la tarea de aislar política y moralmente a los terroristas", así como "definir una política anti-terrorista con un servicio especial para el efecto". En efecto, los diferentes sectores de gobierno

\footnotetext{
18 "La fiebre cívico-militar", Revista Hoy, N 689, del 24 al 30 se septiembre de 1990, p., 6.

19 Boeninger, E. "Informe de análisis al 25 de mayo de 1990", Secretaría General de la Presidencia, FPP, 25 de mayo, 1990, p.7.

20 Arriagada, G. “¿Cómo luchar contra la violencia política?”, FPP, p.1-7.
} 
concordaban en que "se debe perder el 'complejo' respecto de una unidad antiterrorista y proceder a su pronta creación."

Es decir, las bases sobre las cuales el dispositivo CCSP se asienta, estaban previamente configuradas en lo relativo a la posterior Doctrina de Seguridad Ciudadana, pues los acuerdos tomados intra-gobierno también contemplaban: "Realizar los esfuerzos para que en Chile, se invierta en seguridad, tanto el sector público como privado"; y "aprovechar las organizaciones sociales existentes, para educar a la comunidad respecto de seguridad ciudadana". De manera coherente con esto, otra de las tareas fijadas fue: "Mantener la idea fuerza que, quien realiza actos terroristas atenta contra el sistema democrático, y los hechores no gozarán de ningún privilegio"; e "incentivar a través de la Secretaría General de Gobierno, que los actos terroristas no tengan una difusión exagerada y que se evite el sensacionalismo en la información relativa a delitos comunes". Y entre otras medidas, concordaron en que se aplique "régimen carcelario de delincuente común, y si las condiciones lo permiten en recinto de alta seguridad"2 1.

\section{1 de abril de 1991: excepcionalidad en la continuidad}

Pese a la agitación por la explosión de la sensación de temor a inicios de los noventa, las encuestas CEP de 1988 habían demostrado que buena parte de aquellos que votaron por el NO, lo hicieron desconfiando de la capacidad de la Concertación en cuanto a mantener la seguridad pública (Ramos y Guzmán, 2000: 48-49), cuestión de la que buscó hacerse cargo. Sin embargo, junto con esto, 1991 vivió su momento más álgido con el asesinato del senador Jaime Guzmán y los 140 asaltos contabilizados a bancos, propiciando la idea de la existencia de una amenaza en militares, políticos y empresarios (Ramos y Guzmán, 2000: 56-57). De alguna forma el gobierno tuvo que verse compelido a responder por una parte a esa desconfianza que sobre él pesaba y, por otra, a los hechos y los grupos de presión.

En ese marco, Julio Dittborn, presidente de la UDI hacia 1991, consideró, tras los hechos, que "el gobierno ha tenido una actitud débil, poco enérgica frente al terrorismo porque no ha tenido el coraje moral de enfrentar al terrorismo en su propia ley". A su juicio y en términos más drásticos, precisó que "hay gente que no le basta la democracia para exponer sus ideas, sino que siguen usando metralleta y a

\footnotetext{
21 Aylwin, P. "Memorándum de Reunión sobre Delincuencia, Violencia y Terrorismo", FPP, 19 de marzo, 1991, p. 6-13. Este memorándum corresponde a una reunión sostenida entre el Presidente Aylwin, el Ministro del Interior [SR], Ministro Secretario General de Gobierno y Ministro Secretario General de la Presidencia, a la que asisten además Andrés Allamand (UDI), Jorge Arrate (PS), Mario Astorga (PR), Julio Dittborn (UDI), Pedro Esquivel (Alianza de Centro), Gutemberg Martínez (DC), Roberto Muñoz (Social Democracia Progresista), Laura Rodríguez (Alianza Humanista Verde) y Erick Schnake (PPD).
} 
esa gente se le combate con metralleta"22. Así comenzaron las disquisiciones públicas acerca de cómo debía enfrentarse la violencia política, descrita ampliamente como terrorismo.

La reacción inmediata del Senado fue la condena absoluta del hecho. En sesión extraordinaria redacta el día 2 de abril un acuerdo de siete puntos, entre los que se señala que, además de ser un atentado contra la vida de un senador, el hecho constituyó "un acto terrorista que atenta contra la democracia y la paz social", formulando además "un llamado a todos los chilenos para que repudiemos en forma pública este tipo de acciones y logremos -asegura el documento- erradicar en forma definitiva la violencia, la delincuencia y el terrorismo de nuestra vida social y política" 23 .

Así, por ejemplo, la revista Qué Pasa ponía el acento en las experiencias europeas de lucha antiterrorista, asegurando que "así como en Chile el asesinato del líder de la UDI hizo cambiar la posición del gobierno, respecto del combate al terrorismo", sucedió en Alemania y otros países de Europa ${ }^{24}$. No obstante, como hemos mostrado hasta acá, las orientaciones en seguridad y antiterrorismo tienen un lugar de desarrollo previo y de motivaciones locales, no siendo excluyentes.

La prensa daba cuenta de una reunión secreta en el Senado, en la cual "fue el senador designado Sinclair el encargado de explicarles a los ministros que, a su juicio, en Chile se requería un organismo nacional, más eficiente y moderno para dedicarse a este tipo de fines, tal cual lo hacen la mayoría de los países democráticos"25. Sin embargo, como hemos revisado hasta acá, tales inquietudes ya habían tenido la oportunidad de expresarse.

Lo cierto es que, pese a las consideraciones en torno a la actitud del gobierno, este ya venía adoptando y consolidando algunas concepciones en torno a la violencia política, sugiriendo planes de intervención y estrategias de "aislamiento" para los sectores que la practicaban. Como hemos venido exponiendo a través de los sucesivos documentos, estas iniciativas contemplaron la posibilidad de colaboración tanto de la policía, a expensas del posible material acumulado por la CNI, así como de los medios de comunicación. Por lo que, si en algo intervinieron de manera definitiva los hechos, fue precipitando la concreción de toda esta tendencia más general en una determinada política de seguridad que tiene elementos de continuidad y en transformación, presentando similitudes o avances hacia la DSC. De hecho, el propio gobierno aseguró el mismo mes de abril de 1991 que "el escenario que se ha ido configurando pasado el impacto inmediato del asesinato de Jaime

\footnotetext{
22 Grunefeld, Mariana, entrevista a Julio Dittborn, revista Qué Pasa, №1034, 8 de abril de 1991, p.6.

23 Congreso Nacional, "Proyecto de acuerdo", 2 de abril de 1991, p.1-2. Este documento tiene por fecha de publicación el 31 de diciembre de 1991.

24 Qué Pasa, "El arsenal europeo", Nº1045, p. 16.

${ }_{25}$ Qué Pasa, $\mathrm{N}^{\circ} 1034,8$ de abril de 1991, p.12.
} 
Guzmán está fuertemente marcado por la impresión generalizada de que se llegó a un punto de inflexión respecto del tema terrorista y su tratamiento"26.

La estrategia de gobierno fue clara. En sus documentos oficiales declara lo siguiente:

la estrategia político-policial del gobierno persigue (1) resistir la presión del Ejército, que se ha ejercido vía Pinochet, (2) separar aguas entre la derecha y el Ejército, evitando que aquélla se erija en articuladora de la presión de éste, y (3) ganar tiempo para desarrollar capacidades represivas y de inteligencia propias. Queremos insistir, no obstante, que en esta estrategia, tan clara hacia el Ejército y la derecha, no queda igualmente claro lo que debe hacerse con el sector de la izquierda extraparlamentaria ${ }^{27}$.

Entre sus propuestas se encuentra centrar las actividades antiterroristas en la policía de investigaciones y carabineros, sumando a ello una conceptualización democrática del problema, evitando y reemplazando la conceptualización militar de la guerra subversiva, pudiendo hacerse un tránsito más exitoso usando otra, "sin que ello implique un juicio de valor menos drástico del fenómeno, como por ejemplo, la categoría de delito y delincuente terrorista desarrollada por la criminología moderna." No obstante, esta estrategia contemplaba otros dos ejes fundamentales, como por ejemplo el aislamiento de los grupos considerados terroristas respecto de sus bases sociales "toda vez que al asignarles contenidos subversivos, ideológicos o políticos, se contribuye a su mitificación" 28 . Esta tarea es considerada fundamental por el gobierno en la medida que, a su juicio, estimularía la colaboración ciudadana en las tareas policiales y el aislamiento. El segundo de esos pilares es la lucha ideológica mediante la descalificación de los grupos de izquierda "extraparlamentria", "o a partir de la divulgación de una concepción democrática de la seguridad, que sea capaz de sumarlos" 2 . Todo esto, bajo el entendido que "las posibilidades de éxito de la estrategia policial gubernamental dependen en gran medida de acelerar ese proceso de ruptura, para lo cual las dimensiones anotadas de lucha ideológica cobrarán relevancia en el mediano plazo, una vez pasada la urgencia de la actual fase de implementación de nuestra política"30.

De acuerdo a algunos especialistas en los temas de seguridad, violencia y derechos humanos, el asesinato de Guzmán "constituyó una derrota política de

\footnotetext{
26 "Informe de Análisis 12 de abril de 1991", Ministerio Secretaría General de la Presidencia, FPP, p.

2 .

27 Ídem. p.3.

28 Ídem. p.7.

29 Ídem.

30 Ídem. p. 8.
} 
proporciones para sus autores", asegurando además que "se profundizó el consenso político en contra de las acciones terroristas. La muerte de Guzmán debilitó el debate nacional respecto de las violaciones a los derechos humanos ocurridas durante el gobierno militar y lo centró en la violencia terrorista..." (Frühling y Weiser, 1995: 102). Sin embargo, como hemos visto, si en algo este debate se debilitó, esto ocurrió en circunstancias en que el problema del temor ya era un tema central desde 1988, que mostraba un repunte hacia 1990 y que era parte de las tareas políticas asumidas por el nuevo gobierno, incluso antes de conformarse como tal. Y si constituyó un grado de derrota política, esto también se debió a la implementación de una cierta estrategia de consenso político previo que buscó la desvinculación de los actores políticos con los actores sociales y los combatió de forma simultánea mediante la persecución jurídico-policial, pero también ideológicamente.

\section{Los balances}

Recién pasados los hechos, los balances de gobierno se mostraron optimistas respecto del proceso transicional. En mayo de 1991 la Secretaría General de la Presidencia, consideraba que, con todo, "en el país se empieza a respirar un clima de 'fin de transición"”31.

Aseguró también que "un claro ejemplo en este sentido, a la vez que un signo alentador, lo constituye el reforzamiento de la acción partidaria, desde la UDI hasta el PC, la que se encamina en forma creciente por un cauce de expresión democrática" 32 .

En cuanto a la izquierda, el gobierno valoró el carácter de las resoluciones del XVII Pleno del Comité Central del Partido Comunista "en cuanto a fortalecer la acción partidaria dentro de un cauce democrático" 3 .

En efecto, en dichas resoluciones el PCCh también sostuvo que con el asesinato de Guzmán se favoreció a quienes intentaron desplazar la importancia del Informe Rettig y prolongar la impunidad de los responsables por las violaciones de los derechos humanos ${ }^{34}$. Y también señaló que, junto con el terrorismo de Estado, condenaba "el terrorismo de grupos extremistas de izquierda que, infiltrados o no, facilitan enormemente con sus acciones irresponsables los planes de las fuerzas

\footnotetext{
31 "Informe de Análisis 18 de mayo de 1991", Ministerio Secretaría General de la Presidencia, FPP, p.2.

32 Ídem.

33 Ídem.

${ }_{3}$ PCCh, "Resoluciones del XVII Pleno del Comité Central", El Siglo, 12 de mayo de 1991, Separata, p. 3.
} 
reaccionarias"35 y que "somos fervientes partidarios de desterrar definitivamente el uso de las armas y de la violencia política"s6.

Ya en el año 2000 las memorias del Ministerio del Interior aseguraron que entre sus primeras tareas desde 1990 estuvo la desarticulación de los "grupos terroristas", y que "mediante una acción constante, se logró aislar las ideas violentistas dentro del escenario social, desarticular a estos grupos y poner a sus miembros a disposición de la justicia; nada de lo cual se habría logrado sin la adhesión de la sociedad a la acción del Estado"37. Finalmente, en el ítem "Terrorismo", señalan que "controlada la violencia política, el Ministerio del Interior ha desarrollado una serie de iniciativas preventivas", que son: Decreto Supremo 363 que creó el Consejo de Seguridad Pública en 1991; la figura del arrepentimiento eficaz por la ley 19.172 de 1992, la que "permitió ciertos beneficios a terroristas que entregaran información sobre las actividades relevantes de sus organizaciones, y tuvo vigencia cuatro años" y la creación de la Dirección de Seguridad Pública, mediante la Ley 19.212, en $19933^{3}$.

\section{Conclusiones}

A modo de conclusión, podemos señalar que en los ochenta se dio una tendencia a la "coerción de la idea"; que hay un consenso político interno y elaborado de manera previa, en base al supuesto coeficiente de terrorismo en las acciones de violencia política de la izquierda armada ya desde mediados de la década de 1980, el cual, de manera posterior, posibilita la represión del cuerpo orgánico de esos grupos. Es decir, la transposición de las políticas de seguridad de los noventa, que buscó la desarticulación de la izquierda armada, fue fruto de un consenso que apuntó hacia la supresión de las ideas consideradas terroristas, antidemocráticas e irracionales, permitiendo, a su vez, articularlo con concepciones delictuales de ese fenómeno durante la transición. De esta forma, el cambio hacia una nueva doctrina de seguridad (la DSC), está asegurado por ese elemento previo y estimulado por las coyunturas del momento, funcionando estos últimos como hechos propiciatorios de la coerción, que como problema se desarrolla en una larga trayectoria histórica (Valdivia, 2017).

En ese sentido y a propósito de los documentos expuestos, concluimos que el asesinato de Jaime Guzmán fue un hecho coyuntural y propiciatorio de la coerción, voluntad que ya se observaba desde al menos 1983 en los términos de un "terrorismo". Asimismo, estimamos que este proceso de más largo aliento tiende a la

\footnotetext{
35 Ídem. p. 1.

${ }_{3} 6$ Ídem. p. 4. Estas citas fueron recogidas por el documento anteriormente citado, "Informe de Análisis 18 de mayo de 1991", y corroboradas por nosotros en el documento original.

37 “Funciones, Políticas y Gestión 1990 - 2000", Ministerio del Interior, FPP, marzo del 2000, p. 81.

38 Ídem. p. 86-87.
} 
consolidación a partir de 1991. Esa consolidación material que se expresa en la creación del CCSP es, a su vez, expresión de la consolidación de un conjunto de ideas formuladas previamente a los hechos, a propósito de múltiples acontecimientos y en una escala nacional con motivaciones "endémicas". No se niega en modo alguno la influencia doctrinaria exterior. No obstante, se puede observar y desprender de lo expuesto, las disputas políticas y proyectuales a la base de estas propuestas, como resultado del conflicto social cuya expresión más aguda es la violencia política.

Entre las derivadas más relevantes, se encuentra el componente estratégico observable en las iniciativas expresadas en los documentos políticos de gobierno. Nos referimos con esto a la tendencia de la desactivación del conflicto social en la búsqueda de la pacificación política y social. Es decir, la idea misma del aislamiento de los grupos armados de su base social, la criminalización y combate ideológico hablan de una cierta estrategia de contención y desactivación, permitiendo explicar esa transposición desde el CCSP hacia la DSC como un proceso históricamente coherente, en un marco que contiene hechos impredecibles y que propician la toma de algunas decisiones dentro de una relativa continuidad con los afanes represivos de la anterior doctrina contrasubversiva.

\section{Bibliografía}

Acevedo, J. (2017): De la violencia política a la violencia delictual: seguridad ciudadana en el Chile de post-dictadura. 1990-1997. Tesis para optar al grado académico de Magíster en Historia, Mención Historia de América, USACH, Santiago.

Arévalo, B., (2003): Democracia, seguridad y fuerzas armadas en Guatemala: Introducción a las relaciones civiles-militares. Guatemala, FLACSO.

Beroíza, F. (2016): Las Políticas de Seguridad Interna en Chile (1973-2000). Continuidades y readecuaciones en perspectiva histórica. Tesis para optar al grado de Magíster en Historia, Mención Historia de Chile, USACH, Santiago.

Boeninger, E. (1997): Democracia en Chile. Lecciones para la gobernabilidad. Santiago, Editorial Andrés Bello.

Castillo, J. (1986): Democracia y Derechos Humanos. Chile, Instituto de Estudios Humanísticos, Editorial Pehuén.

Celis, S. (2010): Rebeldía y utopía, castigo y represión. Políticas Represivas en el primer gobierno de la Concertación. Reportaje para optar al título de Periodista, USACH, Santiago. 
Dammert, L. (2004): "El gobierno de la seguridad en Chile 1973-2003", pp. 259-282, en L. Dammert (Ed.). Seguridad Ciudadana: experiencias y desafíos. Valparaíso, I. Municipalidad de Valparaíso, Red 14 "Seguridad Ciudadana en la Ciudad", URB-AL.

De Rentemería, I., (2005): "El estado de la seguridad ciudadana en Chile", Revista Polis, 11. Disponible en web: http://journals.openedition.org/polis/5759 [consulta: 20 abril de 2021]

Dirección de Instrucción del Ejército (1984): El Marxismo-Leninismo. Análisis Crítico, Estado Mayor General del Ejército.

Frei Montalva, E. (1984): El mensaje humanista, serie Ensayos, "Libros de HOY", suplemento Revista Hoy. Chile, Fundación Eduardo Frei, Chile.

Fuentes Vera, J. (2009): Los Libros de la Defensa Nacional de Chile 1997-2002 como instrumentos de la política pública. Chile, Academia Nacional de Estudios Estratégicos (ANEPE).

Frühling H. y M. Weiser (1995): "La violencia contra el Estado en Chile: 1976 1991", en H. Frühling (Ed.), El Estado frente al terrorismo. Santiago, Centro de Estudios del Desarrollo, CED, Editorial Atena.

Fuentes Wendling, M. (1981): Terrorismo Comunista. Su accionar en Chile. Chile, Ediciones E.C.O.S., Serie Alerta.

Goicovic, I. (2010): “Transición y violencia política en Chile (1988-1994)”, Revista Ayer, 79, pp. 59-86.

Hens, M. y J. Sanahuja (1995): "Seguridad, Conflictos y Reconversión Militar en América Latina”, Revista Nueva Sociedad, Nº138, pp., 48-69.

Loveman, B. y E. Lira (2000): Las ardientes cenizas del olvido: Vía chilena de reconciliación política 1932-1994, Lom-DIBAM, Santiago.

Maldonado, C. (2002): Servicios de inteligencia en Sudamérica. Estado de situación en perspectiva comparada, Instituto de Cooperación para la Seguridad Hemisférica.

Ministerio del Interior (1987): Latinoamérica Frente al Terrorismo. Santiago, Oficina del Abogado Procurador General de la República, Universidad de Chile.

Pincheira I. (2014). "La doctrina de seguridad ciudadana y la criminalización de la protesta social en Chile pos-dictadura", en Miedo, vigilancia social, alteridad. A 40 
años del Golpe de Estado en Chile. Actas VII Escuela Chile-Francia, Santiago, Universidad de Chile y Embajada de Francia.

Ramos, M. y J. Guzmán (2000): La Guerra y la Paz Ciudadana. Santiago, Lom.

Rosas, P. (2004): Rebeldía, subversión y prisión política. Crimen y castigo en la transición chilena, 1990-2004. Santiago, Lom.

Soto, A. (2009): "La larga sombra del dictador", en F. Camacho Padilla, F. (Ed.), Los legados autoritarios en el Chile post Pinochet. Stockholm Review of Latin American Studies, 5, pp. 5-15.

Tótoro, D. y J. Rebolledo (2021): Rati: Agente de La Oficina. La "Pacificación" en Democracia, Ceibo, Chile.

Valdivia V. (2017): Subversión, coerción y consenso. Creando el Chile del siglo XX (1918-1932). Santiago, Lom.

Sáez, L. (2017): Sociedad Civil en disputa”. Prácticas de gobierno y repertorios de gestión de la izquierda armada a inicios de la Transición democrática en Chile. 19901994. Tesis para optar al grado de Magíster en Ciencias Sociales, Mención en Estudios de la Sociedad Civil, USACH, Santiago.

S/A. (s/f): Insurrección no violenta. Asunción, Instituto Nacional de Estudios Histórico-Culturales, Secretaría FEAL-CENSUR, Editorial Cono Sur.

Varas, A. (1989): "Jaque a la democracia: Terrorismo y anti-terrorismo en las relaciones sociales e internacionales contemporáneas". Chile, Flacso, documento de Trabajo $\mathrm{N}^{\circ} 427$.

\section{Fuentes}

\section{Documentos}

Bases del Diálogo para un Gran Acuerdo Nacional”, 22 de agosto, 1983.

"El Bloque Socialista ante la Profunda Crisis que vive el País", 20 de diciembre de 1984.

"Carta de respuesta del Partido Demócrata Cristiano a la Comisión Política del Partido Comunista", 17 de septiembre de 1986.

Revista Unidad y Lucha, Nº99, diciembre de 1986. 
“Acuerdo Nacional para la Transición a la Plena Democracia”. En: Tagle, M. "Acuerdo Nacional", Corporación Justicia y Democracia, Santiago, 1995.

PCCh, "Resoluciones del XVII Pleno del Comité Central", El Siglo 12 de mayo de 1991, Separata.

“Funciones, Políticas y Gestión 1990 - 2000", Ministerio del Interior, República de Chile, Chile, marzo del 2000.

\section{Fondo digital del Archivo Institucional de la Universidad Alberto Hurtado}

Stange, R. "Correspondencia del General Director de Carabineros de Chile al Presidente Patricio Aylwin", Archivo Período Presidencial, 3 de marzo de 1990.

Boeninger, E. "Informe de análisis al 25 de mayo de 1990", Secretaría General de la Presidencia, Archivo Período Presidencial, 25 de mayo, 1990.

Arriagada, G. "¿Cómo luchar contra la violencia política?", Archivo Período Presidencial.

Aylwin, P. "Memorándum de Reunión sobre Delincuencia, Violencia y Terrorismo", Archivo Período Presidencial, 19 de marzo, 1991.

Congreso Nacional, "Proyecto de acuerdo", 2 de abril de 1991.

"Informe de Análisis 12 de abril de 1991", Ministerio Secretaría General de la Presidencia, Chile.

"Informe de Análisis 18 de mayo de 1991", Ministerio Secretaría General de la Presidencia, Chile.

"Reunión Ejército", 18 de junio de 1991.

\section{Revistas y Periódicos}

Análisis, $\mathrm{N}^{\circ} 73,17$ al 31 de enero, 1984.

Apsi, N ${ }^{\circ} 86,25$ de agosto al 7 de septiembre de 1986.

El Mercurio, 29 de marzo de 1990.

El Mercurio, 22 de junio de 1990.

Análisis, del 7 al 13 de mayo de 1990.

Revista Hoy, N 689 , del 24 al 30 de septiembre de 1990.

Qué Pasa, $\mathrm{N}^{\circ} 1034,8$ de abril de 1991.

Qué Pasa, N¹045, 1991.

Fecha de recepción: 5 de abril de 2021

Fecha de aceptación: 19 de junio de 2021 